\title{
Investigation of Cold Spray on Polymers by Single Particle Impact Experiments
}

\author{
Hanqing Che ${ }^{1} \cdot$ Phuong $\mathrm{Vo}^{2} \cdot$ Stephen Yue $^{1}$
}

Submitted: 24 June 2018/in revised form: 1 October 2018/Published online: 26 November 2018

(c) ASM International 2018

\begin{abstract}
Cold spray has been proven to be a viable method for metallization of polymers and polymer composites, although it has been reported that the mechanism of cold spray on polymeric substrates is different from the mechanism on metallic substrates. In this work, single copper particle impact experiments were performed on polymeric substrates as well as mild steel. Two gas temperatures were selected for each polymer substrate, with one leading to a particle temperature above the glass transition temperature when reaching the substrate and the other below. The particle-substrate interactions on different substrates were analyzed. Based on the results, the mechanism of cold spray on polymeric substrates is discussed and compared to that on metallic substrates.
\end{abstract}

Keywords cold spray - metallization of polymers . polymeric substrate $\cdot$ single particle impact

This article is an invited paper selected from presentations at the 2018 International Thermal Spray Conference, held May 7-10, 2018, in Orlando, Florida, USA, and has been expanded from the original presentation.

\section{Hanqing Che}

hanqing.che@mail.mcgill.ca

1 Department of Mining and Materials Engineering, McGill University, Montreal H3A 0C5, Canada

2 National Research Council Canada, Boucherville J4B 6Y4, Canada

\section{Introduction}

Metallization of polymers has received increasing attention in a wide range of applications during the past few decades (Ref 1). In the early 1990s, the evolution in microelectronics industry stimulated intensive research on this topic due to the great need for miniaturization and reduction of propagation delay in devices consisting of copper and polymers (Ref 2). For such applications, metals were usually evaporated onto polymers (Ref 2). More recently, polymers and polymeric composites have been increasingly used as structural materials, e.g., in the aerospace industry, due to their low density and high specific strength, but the low conductivity has limited their application (Ref 1,3). Hence, metallization of large-scale polymers and polymeric composites have been studied, and a number of coating technologies have been investigated (Ref 1, 4, 5). Among these technologies, cold spray has been demonstrated to be a feasible approach to metallize polymers and polymeric composites (Ref $3,6,7,8,9,10,11,12,13)$. In particular, cold spray features low processing temperatures, which will minimize the thermal damage to the polymeric substrates compared to other thermal spray technologies.

Despite the fact that successful coatings have been produced by cold spray onto various polymeric substrates, the deposition mechanism of metals on polymers is not thoroughly understood. Conventionally, when cold spraying metals onto metallic substrates, the particles are considered to be bonded by a combination of mechanical interlocking and metallurgical bonding (Ref $14,15,16,17,18,19)$. It is widely accepted that the bonding is achieved through the adiabatic shear instability mechanism (Ref 14, 16). However, when it comes to the polymeric substrates, the adiabatic shear instability 
mechanism may not be applicable since the polymers possess largely different mechanical properties when compared to metals; indeed, such a mechanism has barely been observed in experiments ( $\operatorname{Ref} 3,20,21)$. Therefore, it is of importance to understand the deposition mechanism for cold spray on polymeric substrates; then, a generic method can be generated to practically determine the feasibility of cold spraying a specific metal/polymer combination. In a recent paper (Ref 20), we have proposed that cold spray on polymeric substrates should be considered as a two-step process, the development of the first layer followed by the buildup, and each step has its own window. For the development of the first layer, the particle velocity must reach the onset velocity for particle/substrate interlocking, whereas to deposit a thick coating, the conventional critical velocity must be exceeded, while the particle velocity should remain below the velocity limit above which the incoming particles will erode the previously deposited layer. As the buildup step is, to some extent, similar to the deposition in conventional cold spray on metals, the development of the first layer on polymeric substrates is critical and more research is required to study the formation of particle/substrate interlocking. Single particle impact tests can help to understand how the first layer is developed. Those tests have previously been used to investigate the particle/substrate interaction upon impact, and such a test enables a clear observation of the particle deformation, i.e., splat formation, in conventional cold spray (Ref 22, 23).

Polymers can be classified into two groups, thermoplastics and thermosets, and they have different deformation responses and different thermal processing behaviors. It has been reported that cold spray onto thermoplastics is more successful than thermosets (Ref 20, 21, 24). For example, a number of metals, including copper (Ref 20, 21, 25), aluminum ( $\operatorname{Ref} 26,27)$, titanium (Ref 24), and tin (Ref 20,21, 28), have been successfully cold sprayed onto various thermoplastics. On the other hand, substrate erosion has been reported as a key issue for thermosets or thermoset matrix composites; only tin can be directly deposited but with a narrow deposition window (Ref $3,10,21)$. This discrepancy is attributed to the existence of the relatively abrupt thermal softening for thermoplastics near/above their glass transition temperatures, $T_{\mathrm{g}} \mathrm{s}$ (Ref $20,21)$.

This work aims at studying the cold spray deposition behavior of metals on polymers by doing single particle impact tests. In particular, this paper concentrates on how the first layer is developed on the polymer surfaces. Copper particles were cold sprayed onto various polymeric substrates. In particular, the gas temperatures varied for each substrate and were chosen according to fluid dynamics calculations, such that the particles can reach the substrate at temperatures above and below the $T_{\mathrm{g}} \mathrm{s}$ of the thermoplastic polymers. The interaction between the copper particles and the polymeric substrates was observed, and the deposition behavior was discussed. The effect of particle temperature, with regard to $T_{\mathrm{g}}$ of the thermoplastic polymers, was also evaluated.

\section{Experimental Methods}

\section{Starting Materials}

Commercial-purity copper powder (Plasma Giken, Japan) was used as the feedstock powder in this work. The average particle size is $18 \mu \mathrm{m}$, as measured with a laser scattering particle size analyzer (LA-920, HORIBA, Japan). The scanning electron microscope (SEM) image and particle size distribution of the copper powder are shown in Fig. 1. It can be seen that the copper particles are generally spherical, but the particle surfaces are not smooth.

Five substrates were used in this work, namely mild steel, CFRP and three thermoplastics. Mild steel was used
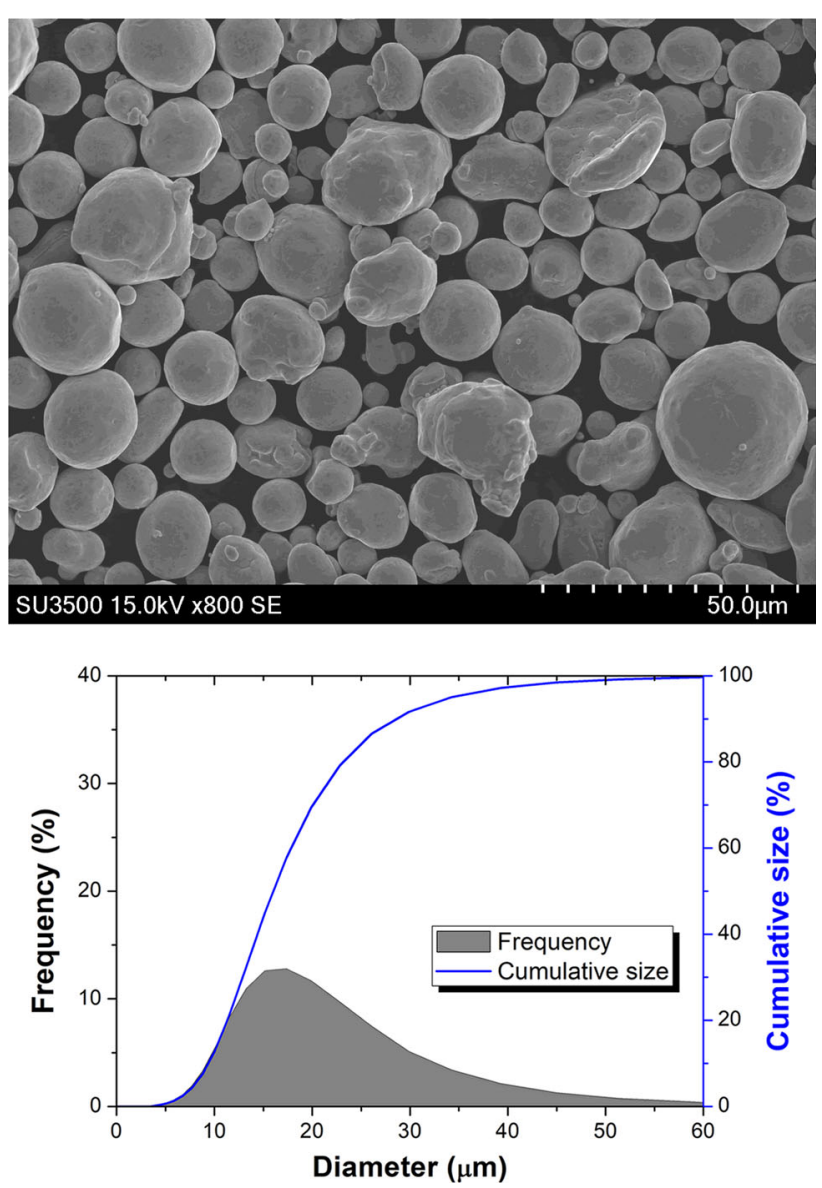

Fig. 1 Scanning electron microscope image (top) and particle size distribution (bottom) of the feedstock powder 
as a benchmark substrate. The CFRP materials used in this work were supplied by Bombardier Aerospace (Bombardier, Canada) and have a thermosetting matrix and continuous carbon fiber reinforcements. The three thermoplastic substrates were commercially available ABS (acrylonitrile butadiene styrene), PEEK (polyether ether ketone) and PEI (polyethylenimine). The three thermoplastic polymers have different glass transition temperatures, $T_{\mathrm{g}} \mathrm{s}$, as well as different mechanical properties, as listed in Table 1. Prior to the cold spray experiments, the CFRP and mild steel sections were degreased with acetone, and the ABS, PEEK and PEI sections were degreased with ethyl alcohol (otherwise may dissolve into acetone due to their relatively high sensitivity to acetone).

\section{Single Particle Impact Cold Spray}

Single particle impact cold spray experiments were carried out at the McGill-NRC cold spray facility at National Research Council Canada, Boucherville using a commercially available Plasma Giken system (PSC-800, Plasma Giken, Japan). The process parameters are listed in Table 2. Nitrogen was selected as the carrier gas, and the gas pressure was fixed at $2 \mathrm{MPa}$. A nozzle stand-off distance of $40 \mathrm{~mm}$ was used. Before cold spraying, the commercially available CKinetic Spray Solutions (KSS) software (Kinetic Spray Solutions, Germany) was used to simulate the process and calculate the particle temperatures, $T_{p} \mathrm{~s}$ [details of the simulation reported in (Ref 18, 29)]. The software's fluid mechanics module enables the calculation of velocities and temperatures of the gas and particle at the set process conditions (for a given nozzle and defined powder characteristics). The system parameters (e.g., nozzle geometry, powder inject location) were kept the same as the Plasma Giken system, and the process parameters (e.g., gas pressure, stand-off distance) were identical to those that would be used in the single impact tests. Based on the simulation results, two gas temperatures (gas temperature in this paper refers to that in the converging part of the nozzle, i.e., before the throat) were selected for each polymer substrate, with one leading to a particle temperature (for mean particle size) above $T_{\mathrm{g}}$ when

Table 1 Some properties of the three thermoplastic materials used in this work, data summarized from (Ref 33$)$

\begin{tabular}{llll}
\hline Property & ABS & PEEK & \multicolumn{1}{c}{ PEI } \\
\hline$T_{\mathrm{g}},{ }^{\circ} \mathrm{C}$ & 105 & 145 & 215 \\
Hardness, M & $30-50$ & $55-100$ & $109-112$ \\
Tensile strength, MPa & $30-60$ & $70-100$ & $90-100$ \\
ASTM D256 impact, J/m & $100-350$ & $80-85$ & $50-60$ \\
\hline
\end{tabular}

reaching the substrate and the other below. The results of the simulation and the rationale for the experimental design are presented in "Simulation and Gas Temperature Selection" section. For CFRP (cannot reflow when heated), gas temperatures of 425 and $250{ }^{\circ} \mathrm{C}$ were used, and $425^{\circ} \mathrm{C}$ was chosen for steel.

To achieve single particle impact and avoid successive impingement, a high gun travel speed of $1000 \mathrm{~mm} \mathrm{~s}^{-1}$ and low powder feed setting, no higher than 0.2 RPM, were used. At such a high gun travel speed, the thermal effect, i.e., heating, would be different from the previous experiments (Ref 20) in which successful coatings were obtained at a much lower gun travel speed $\left(25 \mathrm{~mm} \mathrm{~s}^{-1}\right)$. Considering that the thermal effect may be important for polymeric substrates, a preheating pass was conducted just before the single impact tests to minimize the difference in heating. Namely, the gun was operated at the set condition but without powder feeding and moved across the substrate at $25 \mathrm{~mm} \mathrm{~s}^{-1}$, followed immediately by the single impact spray as a return pass at $1000 \mathrm{~mm} \mathrm{~s}^{-1}$ with powder feeding.

After the cold spray experiments, the samples were characterized with a Hitachi SU 3500 SEM in variable pressure mode (due to the low electrical conductivity of the polymers).

\section{Results and Discussion}

\section{Simulation and Gas Temperature Selection}

The simulation results from the CKSS software at a fixed gas pressure of $2 \mathrm{MPa}$ are shown in Fig. 2. The calculated particle temperatures at corresponding gas temperatures are also listed in Table 2. The particle temperatures and velocities presented are those for the mean particle size at $40 \mathrm{~mm}$ from the nozzle exit (when reaching the substrate in experiments). It can be seen from Fig. 2 that both the particle temperature and velocity increase generally linearly with the gas temperature. The particle temperature increases more significantly than particle velocity, e.g., $T_{p}$ is five times higher at $550{ }^{\circ} \mathrm{C}$ than $250{ }^{\circ} \mathrm{C}$, whereas the particle velocity only increases by $21 \%$.

The gas temperatures for each substrate were selected based on the simulation results, and the rationale is as follows. It was proposed in our previous paper that cold spray onto the polymeric substrate is a two-step process, each step has its own window and the overall window for a non-monolayer coating is where the two windows overlap (Ref 20). However, it is relatively difficult to practically determine the window for developing the first layer. One main reason is that the properties of polymers change largely with temperature. For thermoplastics, their properties 
Table 2 Process parameters for single particle impact cold spray tests (Calculated particle velocities are from @KSS simulation and are rounded to the nearest 5 or 10)

\begin{tabular}{|c|c|c|c|c|c|}
\hline Substrates & Temperature, ${ }^{\circ} \mathrm{C}$ & Calculated $T_{p},{ }^{\circ} \mathrm{C}$ & Pressure, $\mathrm{MPa}$ & Stand-off distance, $\mathrm{mm}$ & Gun travel speed, $\mathrm{mm} \mathrm{s}^{-1}$ \\
\hline Steel & 425 & 155 & 2 & 40 & 1000 \\
\hline PEI & 550,425 & 235,155 & & & \\
\hline PEEK & 425,350 & 155,110 & & & \\
\hline ABS & 400,250 & 140,45 & & & \\
\hline CFRP & 425,250 & 155,45 & & & \\
\hline
\end{tabular}

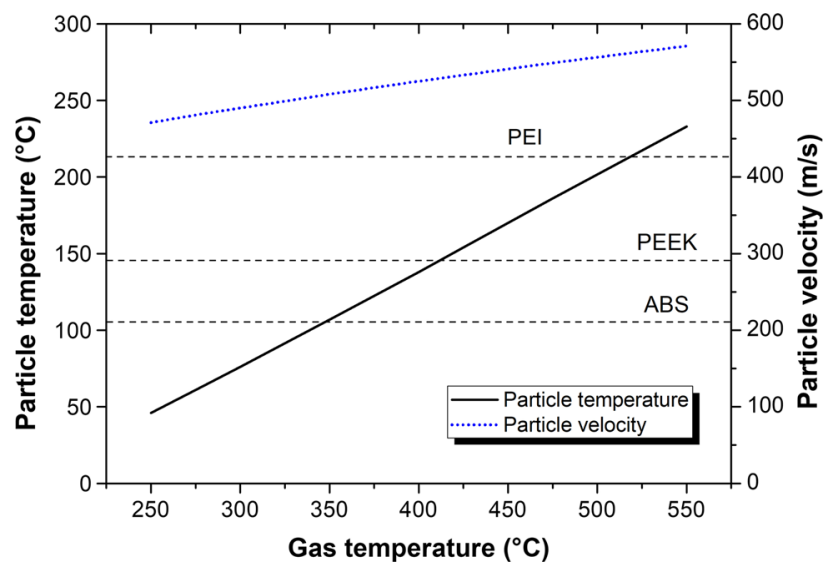

Fig. 2 Particle temperature and velocity results as a function of gas temperature, calculated by the $\odot$ KSS software (dashed lines showing $T_{\mathrm{g}} \mathrm{s}$ of the thermoplastics)

show a relatively sudden change at $T_{\mathrm{g}}$. Thus, it is worthwhile comparing the impact behavior at particle temperatures above and below $T_{\mathrm{g}}$. Based on the simulation results, gas temperatures of 550 and $425^{\circ} \mathrm{C}$ were chosen for PEI, 425 and $350{ }^{\circ} \mathrm{C}$ for PEEK, and 400 and $250{ }^{\circ} \mathrm{C}$ for ABS (The $T_{\mathrm{g}} \mathrm{s}$ of the three thermoplastics are presented in Fig. 2 by the dashed lines). The particle temperature margins with respect to $T_{\mathrm{g}}$ of each thermoplastic were not intentionally kept the same in this qualitative study (There are various uncertainties, e.g., $T_{p}$ varies with particle size, glass transition occurs within a range of temperatures instead of one temperature). For CFRP, which has a thermosetting matrix, 425 and $250{ }^{\circ} \mathrm{C}$ were used, which result in a $108{ }^{\circ} \mathrm{C}$ difference in particle temperature according to the simulation. Theoretically, the particle velocity should be identical when comparing the effect of particle temperature (i.e., decrease gas pressure at higher temperatures to compensate the velocity increase); the velocity increase was considered negligible in this work for simplification purpose (velocity within $8 \%$ for a $100{ }^{\circ} \mathrm{C}$ interval).

With the calculated particle velocity and temperature, the software may further calculate a deposition efficiency (DE) by comparing the particle velocity to the conventional critical velocity, $v_{\text {crit }}$, at that temperature. The $\mathrm{DE}$

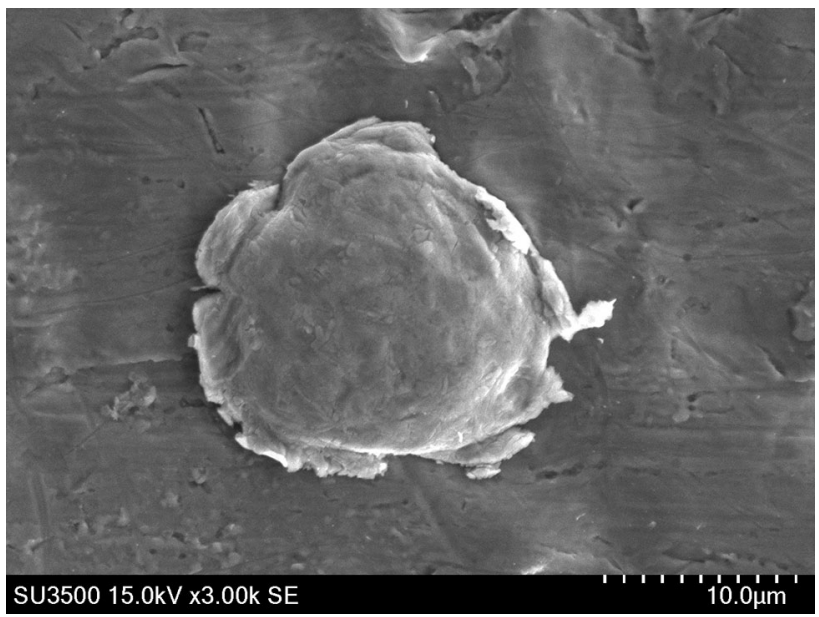

Fig. 3 SEM image showing a copper particle cold sprayed onto the steel substrate at $425{ }^{\circ} \mathrm{C}$

calculation assumes that the particle and substrate materials are identical (Ref 30), so the results will be different on polymeric substrates. Nevertheless, the calculated DE results (not shown, $\sim 50 \%$ at $250{ }^{\circ} \mathrm{C}, \sim 90 \%$ at $350{ }^{\circ} \mathrm{C}$, then increases slightly) suggest that the process conditions used in this work are all within the conventional cold spray window [i.e., the buildup window according to (Ref 20)]. This means if the first layer can be developed, it is then theoretically possible to build up a thick coating under those conditions.

\section{SEM Characterization}

\section{Steel}

Figure 3 shows the SEM image of a copper particle cold sprayed onto the steel substrate at $425{ }^{\circ} \mathrm{C}$. The splat formation is well captured. It can be seen that the particle successfully adhered to the substrate, showing obvious flattening and a significant amount of plastic deformation, especially at its rim. This indicates that the adiabatic shear instability was activated and is in accordance with the simulation results (i.e., particle velocity higher than critical velocity). A trial cold spray of copper at such a condition 
led to successful coating deposition. However, such plastic deformation and particle flattening were not observed on the polymeric substrates, even when spraying under the same condition.

\section{PEI}

For all the polymeric substrates, the copper particles found at the top surfaces do not show significant amounts of plastic deformation. Figure 4 presents the copper particles cold sprayed at 550 and $425{ }^{\circ} \mathrm{C}$ on PEI substrates. The former led to a particle temperature of $\sim 235^{\circ} \mathrm{C}$ and the latter $\sim 155^{\circ} \mathrm{C}$. It can be seen from Fig. 4(a) and (b) that both particles penetrated the substrates and remained adhered, without significant particle deformation (e.g., flattening). There are 'interaction' zones in the substrate around the particles and clear signs of substrate deformation in both samples. The interaction zone is larger at higher temperature (Fig. 4a). The substrate deformation should be caused by a combination of thermal softening (e.g., melting) and deformation under force (e.g., plastic deformation). There is no significant difference between the two samples in Fig. 4(a) and (b), even though one has a particle temperature above $T_{\mathrm{g}}$ and the other below. On the other hand, the two substrates exhibit differences where particle bouncing occurred, as shown in Fig. 4(c) and (d). At $550{ }^{\circ} \mathrm{C}$, it can be seen that the bouncing copper particle was 'smeared' or 'drawn' over the polymer in Fig. 4(c). Melting of PEI at the impact site had occurred, and adhesion had been achieved. Whereas at $425{ }^{\circ} \mathrm{C}$, it shows two craters in Fig. 4(d) with no copper particles being held. From the center of the craters, some stringy/fibrous structures are observed. This is similar to the 'Spinnbarkeit' phenomenon (a rheological term refers to the spinnability of viscoelastic fluids) and is likely formed by attaching/ melting, bouncing/drawing and detaching/solidifying. Thus, it implies that localized melting has occurred despite the fact that the calculated particle temperature immediately before impact is lower than the $T_{\mathrm{g}}$ of PEI. It should also be pointed out that the copper particles in Fig. 4 (and other figures in this section) look different from those in Fig. 1, and this may be caused by thermal etching [(i.e., formation of facets and grain boundary grooves at metal surfaces when subjected to high temperature and suitable environments, $(\operatorname{Ref} 31)$ ], or it may also be attributed to that the SEM images of the polymeric substrates were in BSE mode (SE for feedstock powder).
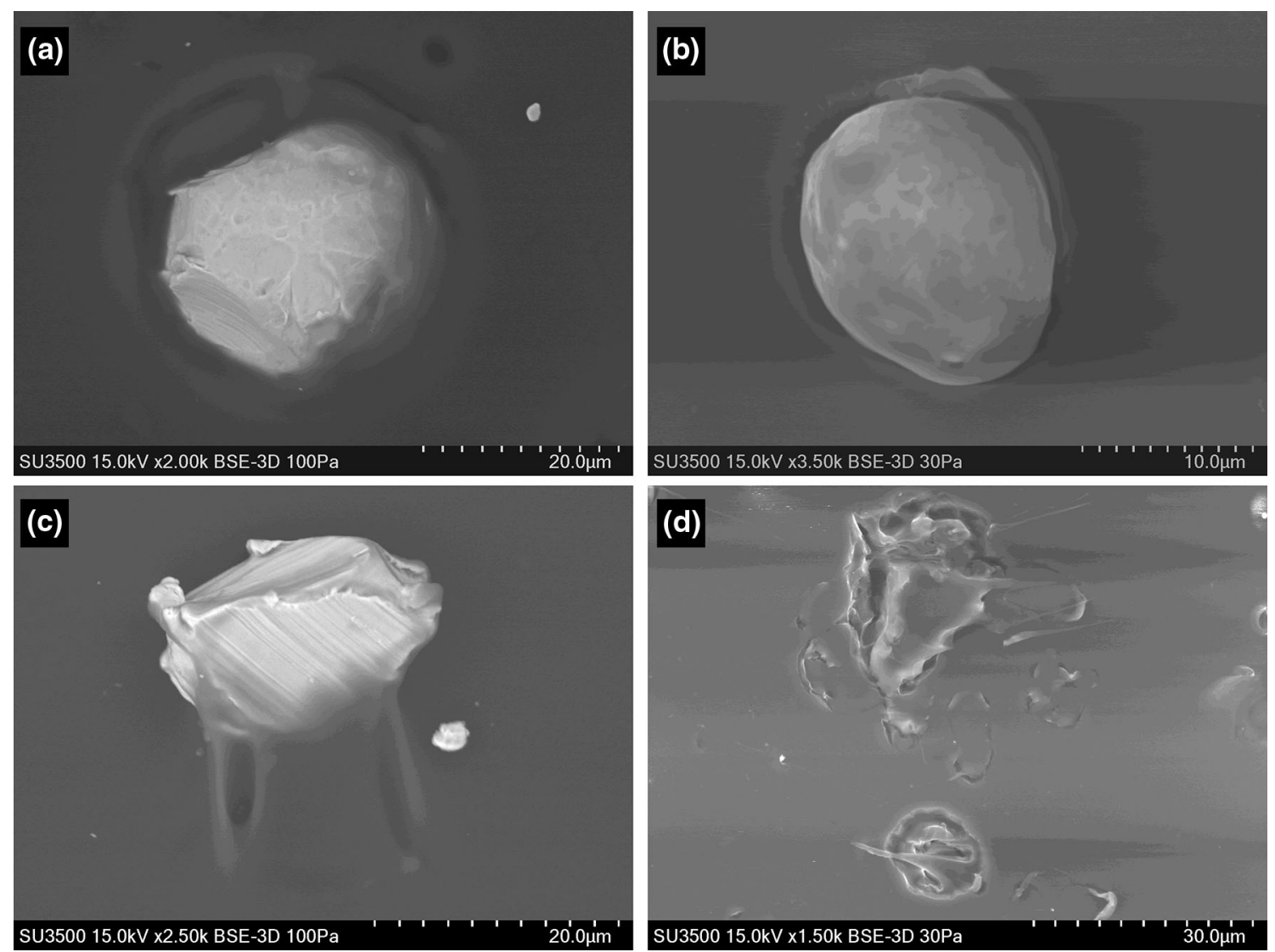

Fig. 4 SEM images showing copper particles cold sprayed onto PEI (a-c) and the craters at the PEI surface (d): $550{ }^{\circ} \mathrm{C}(\mathrm{a}, \mathrm{c})$ and $425{ }^{\circ} \mathrm{C}(\mathrm{b}, \mathrm{d})$ 
Cold spray of copper at $425^{\circ} \mathrm{C}$ on PEI can result in successful coating, but delamination of the coating was observed in previous work (Ref 20). The delamination may be related to inadequate substrate melting or particle penetration, according to the single impact observation in this work. Hence, it is inferred that increase either gas temperature or pressure may help to improve bonding between copper and PEI.

\section{PEEK}

For PEEK cold sprayed at 425 and $350{ }^{\circ} \mathrm{C}$, the results are shown in Fig. 5. The copper particles found in both samples basically remain spherical. It can be seen from Fig. 5(a) that a copper particle is anchored in the substrate surface at $425{ }^{\circ} \mathrm{C}$, with an obvious substrate interaction zone around the particle. Cold spray of copper at this temperature led to successful thick coatings (Ref 20). At a lower temperature of $350{ }^{\circ} \mathrm{C}$, the interaction zone around the adhered particle can barely be observed in the substrate, as shown in Fig. 5(b). It is likely that the particle did not penetrate the substrate at $350{ }^{\circ} \mathrm{C}$ but attached superficially instead, which signifies inadequate anchorage. Indeed, significantly fewer particles remain adhered at the lower temperature, leaving more craters in the sample. A closer look at the craters after the particles bounced off is shown in Fig. 5(c). The crater is similar to that in Fig. 4(d), as some cavities and the 'Spinnbarkeit' phenomenon can be observed. This suggests that some localized substrate melting and bonding has been achieved at the impact sites, but is inadequate to hold the particles. It should be mentioned that during the SEM characterization of the $350{ }^{\circ} \mathrm{C}$ sample, some adhered copper particles were swept away from the substrate by the electron beam, signifying weak adhesion to the substrate. This is understandable considering that: (a) the particle temperature, $107^{\circ} \mathrm{C}$, is well below $T_{\mathrm{g}}$, and (b) PEEK is a semicrystalline thermoplastic in which the crystalline part does not gradually soften with temperature increase (Ref 32). Based on these observations, it is inferred that higher particle velocity or temperature may be beneficial for stronger anchorage/ interlocking than at $350{ }^{\circ} \mathrm{C}$ and $2 \mathrm{MPa}$. However, single particle impact is not practical, whereas successive impact is more realistic in practice, for which good bonding may still be achieved.
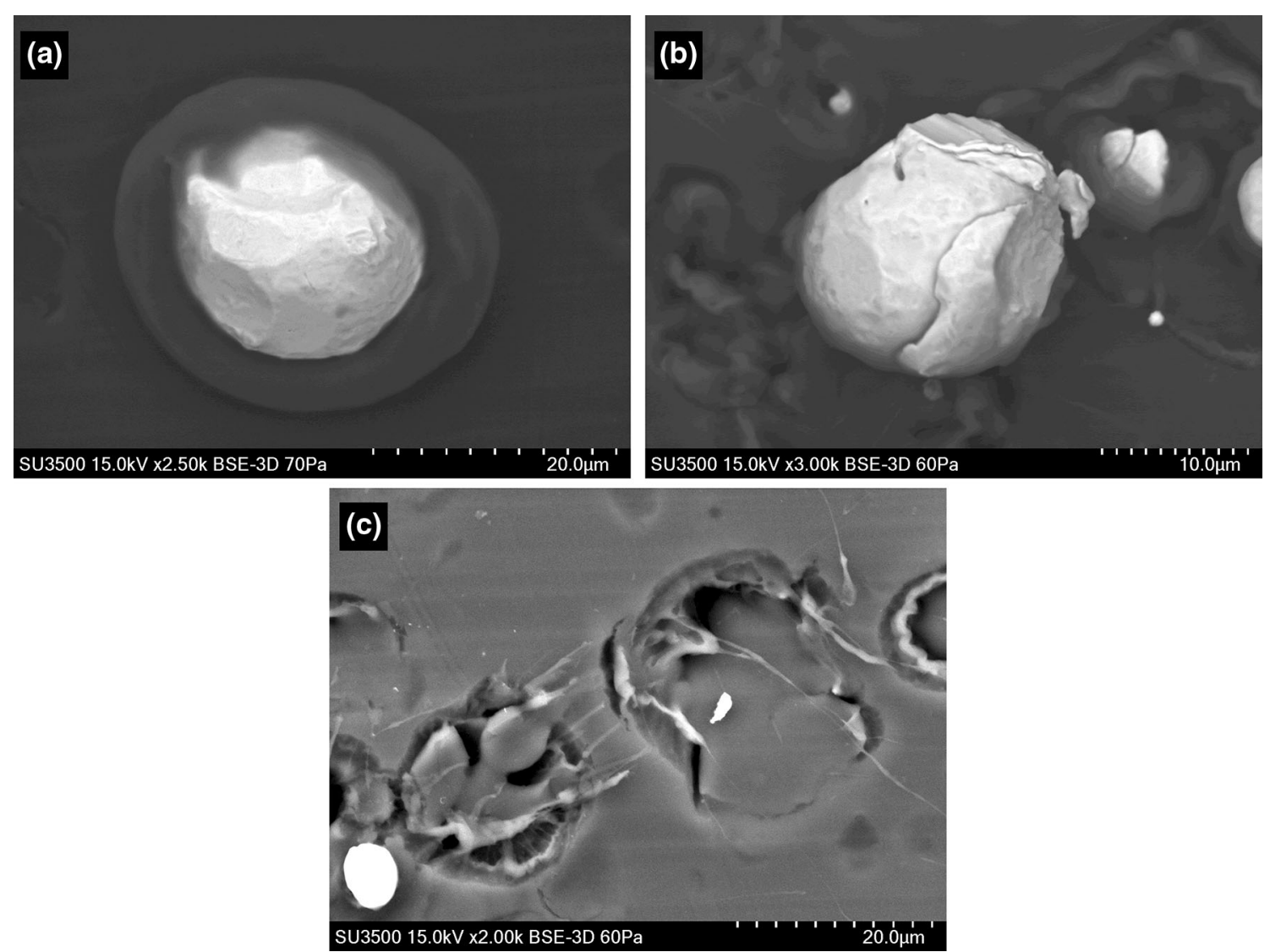

Fig. 5 SEM images showing copper particles cold sprayed onto PEEK at $425{ }^{\circ} \mathrm{C}$ (a) and $350{ }^{\circ} \mathrm{C}$ (b), and the craters at the PEEK surface at $350{ }^{\circ} \mathrm{C}(\mathrm{c})$ 
$A B S$

The SEM images showing the ABS substrates after single impact tests are presented in Fig. 6. After cold spraying at $400{ }^{\circ} \mathrm{C}$, a copper particle was found penetrated deeply into the substrate. This may be attributed to the weak resistance to heat of ABS. It implies that cold spray of copper at temperatures higher than $400{ }^{\circ} \mathrm{C}$ can cause severe substrate erosion. Indeed, severe erosion was observed in the previous work when cold spraying copper onto $\mathrm{ABS}$ at $425{ }^{\circ} \mathrm{C}$ (Ref 20). At a lower temperature of $250{ }^{\circ} \mathrm{C}$, particle adherence and the associated interaction zones can be observed. The particles that remain attached are mainly fine particles at $250{ }^{\circ} \mathrm{C}$. Particle detachment also occurred at some locations, leaving a few craters at the substrate surface. The 'Spinnbarkeit' can also be seen at some craters (not shown), indicating that local melting had occurred upon impact, even though the calculated particle temperature is lower than of $T_{\mathrm{g}}$. A trial spray of copper at $250{ }^{\circ} \mathrm{C}$ and $2 \mathrm{MPa}$ failed to deposit continuous coating due to substrate erosion. Future work on cold spraying of metals onto ABS requires careful selection of the temperature/pressure combination, such that severe erosion can be avoid while good interlocking can be achieved.

\section{CFRP}

Unlike the thermoplastics, the CFRP used in this work has a thermosetting matrix. The CFRP samples after single impact tests at 425 and $250{ }^{\circ} \mathrm{C}$ are shown in Fig. 7. It can be seen that at both temperatures, cavities have been generated adjacent to the copper particles in the substrates after impact. The cavity formation probably results from the brittleness of the CFRP substrate. Because of the cavity formation, the particles are not securely anchored, as can be seen from Fig. 7; it is reasonable to believe that if there were successive impacts, the particle would have been removed and enlargement of the cavity (i.e., erosion) would have occurred. The results signify that erosion of the substrate, instead of coating deposition, can occur during cold spraying of copper on CFRP at similar conditions. This is confirmed by the experimental results in $(\operatorname{Ref} 3,20)$.

\section{Discussion on the Deposition Behavior}

In general, it can be seen that the copper particles did not experience significant amounts of plastic deformation on the polymeric substrates, even though the process conditions were selected within the conventional cold spray window (i.e., adiabatic shear instability should occur on metallic substrates). This confirms that the conventional adiabatic shear instability mechanism is inapplicable when developing the first metallic layer on polymeric substrates. For polymeric substrates, the particles penetrated the polymers and generally remained spherical in this work. Good particle/substrate interlocking may be achieved when the substrate shows good capability of thermal deformation (e.g., PEI and PEEK in this work). This may result from the local softening of the thermoplastics, which has been observed by various researchers (Ref 20, 21, 24). For thermosets or thermoset matrix composites (e.g., CFRP in this work), which lack the ability of thermal deformation or reflow, particle/substrate interlocking is relatively difficult due to the brittleness of the substrate. In addition, the polymer's resistance to erosion at relatively high temperature is another important factor. An example of this is ABS in this work, on which coating attempts failed with particle temperatures both above and below its $T_{\mathrm{g}}$, even though ABS is a thermoplastic and can be thermally softened. Therefore, other mechanical properties apart from thermal softening, such as substrate susceptibility to erosion, can also govern the deposition process. For future work, the correlation between the deposition behavior and
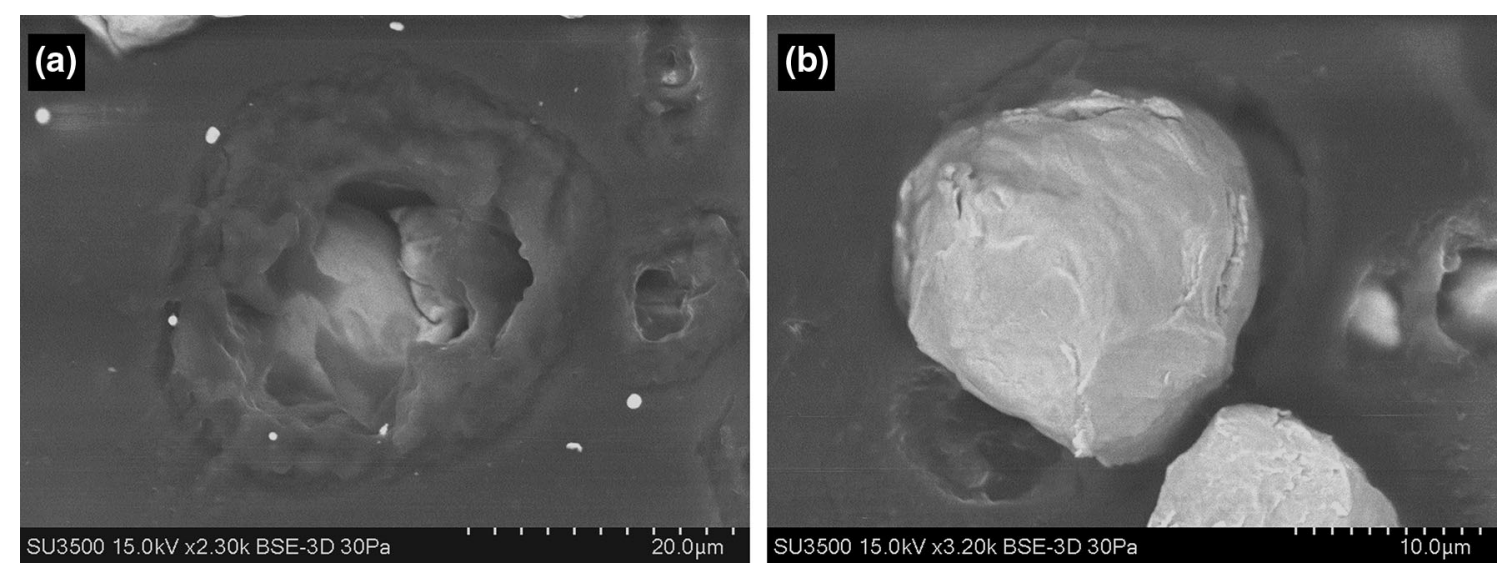

Fig. 6 SEM images showing copper particles cold sprayed onto ABS at $400{ }^{\circ} \mathrm{C}$ (a) and $250{ }^{\circ} \mathrm{C}$ (b) 

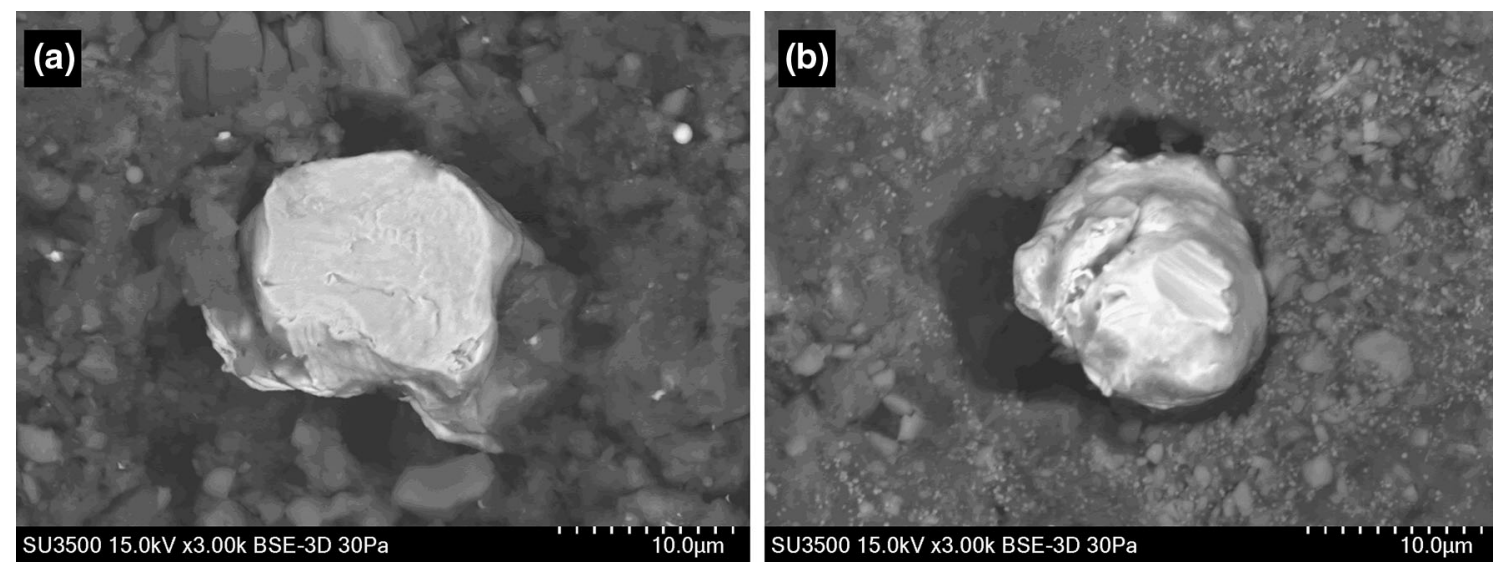

Fig. 7 SEM images showing copper particles cold sprayed onto CFRP at $425{ }^{\circ} \mathrm{C}$ (a) and $250{ }^{\circ} \mathrm{C}$ (b)

various mechanical properties of polymers at different temperatures is recommended.

Without significant particle deformation, the bonding can only be achieved by mechanical interlocking/anchorage between the first metallic layer and the polymers. From another point of view, substrate damage is necessary, but must be to the right extent. Excessive damage can lead to severe substrate erosion (e.g., ABS at $400{ }^{\circ} \mathrm{C}$ ), whereas insufficient damage may result in no/poor bonding (e.g., PEI at $425{ }^{\circ} \mathrm{C}$ ). Similar to conventional cold spray, the two main parameters that influence bonding between metal and the polymer substrates are velocity and temperature. Chen et al. recently reported the effect of pressure/velocity on single particle deposition during cold spray of copper on PEEK (Ref 25). It was found that with increasing gas pressure/particle velocity but fixed gas temperature, the copper particles penetrated deeper into PEEK and more wrinkles and jets formed in the PEEK substrate around the copper particles. This trend may be attributed to both more mechanical penetration (higher kinetic energy) and more thermal softening (kinetic energy dissipation induced temperature increase). In this work, the gas temperature was varied and the pressure was kept unchanged. It is inevitable that increasing gas temperature will lead to increasing particle velocity at the same gas pressure, but the particle temperature increase is much more significant than particle velocity. It is reasonable to believe that the differences at different gas temperatures observed in this work are due to the temperature difference. Based on the results of this work, it can be seen that varying the particle temperature in the vicinity of $T_{\mathrm{g}}$ may effectively alter the bonding condition of metals on a thermoplastic. Nevertheless, it is also true that thermal softening and mechanical penetration occur simultaneously and are difficult to differentiate, although one may be dominant.

Cold spray of metal on polymer substrates is different from cold spray of hard metal on relatively softer metals.
One major difference is due to the glass transition of thermoplastics, at temperatures above $T_{\mathrm{g}}$ the thermoplastics almost lose all their mechanical properties. This is similar to the melting of metals, but the melting points of metals are barely reached during cold spray, even in the adiabatic deformation area. Another major difference between polymers and soft metals is the largely different thermal conductivity (a few orders of magnitudes lower for polymers). Heat generated at the metal/polymer interface cannot be dissipated as fast as at the metal/metal interface. This can make the thermal effect even more significant on polymeric substrates. It is of interest to monitor/simulate the polymer substrate surface temperature near the particle interface during cold spray for further studies.

\section{Conclusions}

Single particle impact tests were performed by cold spraying copper onto various polymeric substrates. The gas temperatures were chosen from the conventional deposition window calculated by software simulation. Results show that the copper particle did not experience significant plastic deformation upon impact with the polymeric substrates, which are very different from mild steel. In general, the particle/substrate interlocking was achieved on all three thermoplastic polymers: the particle penetrated the substrate with an interaction zone around it. The deformation in the substrates is caused by a combination of thermal softening and deformation under force. On the other hand, cavities were formed in the CFRP substrate at the impact spots, which is a sign of erosion, and the particles were not firmly interlocking with the substrate. For thermoplastics, cold spraying at a particle temperature higher than $T_{\mathrm{g}}$ can lead to relatively deep particle penetration into the substrate and good particle/substrate interlocking, whereas below $T_{\mathrm{g}}$ the anchorage may be insufficient. 
Acknowledgment The authors wish to acknowledge the financial support of Natural Sciences and Engineering Research Council of Canada. Bombardier Aerospace is acknowledged for providing the CFRP materials. Mr. Jean-François Alarie from National Research Council Canada, Boucherville, is acknowledged for his contribution to the cold spray experiments.

\section{References}

1. R. Gonzalez, H. Ashrafizadeh, A. Lopera, P. Mertiny, and A. McDonald, A Review of Thermal Spray Metallization of Polymer-Based Structures, J. Therm. Spray Tech., 2016, 25(5), p 897919

2. F. Faupel, V. Zaporojtchenko, T. Strunskus, J. Erichsen, K. Dolgner, A. Thran, and M. Kiene, Fundamental aspects of polymer metallization, Metallization of Polymers, 2nd ed., E. Sacher, Ed., Springer, New York, 2002, p 73-96

3. H. Che, P. Vo, and S. Yue, Metallization of Carbon Fibre Reinforced Polymers by Cold Spray, Surf. Coat. Technol., 2017, 313, p 236-247

4. A. Rezzoug, S. Abdi, A. Kaci, and M. Yandouzi, Thermal Spray Metallisation of Carbon Fibre Reinforced Polymer Composites: Effect of Top Surface Modification on Coating Adhesion and Mechanical Properties, Surf. Coat. Technol., 2018, 333, p 13-23

5. F. Oliveira, N. Dencheva, P. Martins, S. Lanceros-Méndez, and Z. Denchev, A New Approach for Preparation of Metal-Containing Polyamide/Carbon Textile Laminate Composites with Tunable Electrical Conductivity, J. Mater. Sci., 2018, 53(16), p 11444-11459

6. G. Archambault, B. Jodoin, S. Gaydos, and M. Yandouzi, Metallization of Carbon Fiber Reinforced Polymer Composite by Cold Spray and Lay-Up Molding Processes, Surf. Coat. Technol., 2016, 300, p 78-86

7. J. Affi, H. Okazaki, M. Yamada, and M. Fukumoto, Fabrication of Aluminum Coating onto CFRP Substrate by Cold Spray, Mater. Trans., 2011, 52(9), p 1759-1763

8. A. Astarita, L. Boccarusso, M. Durante, A. Viscusi, R. Sansone, and L. Carrino, Study of the Production of a Metallic Coating on Natural Fiber Composite Through the Cold Spray Technique, $J$. Mater. Eng. Perform., 2018, 27(2), p 739-750

9. R. Kromer, Y. Danlos, E. Aubignat, C. Verdy, and S. Costil, Coating Deposition and Adhesion Enhancements by Laser Surface Texturing-Metallic Particles on Different Classes of Substrates in Cold Spraying Process, Mater. Manuf. Process., 2017, 32(14), p 1642-1652

10. H. Che, X. Chu, P. Vo, and S. Yue, Cold Spray of Mixed Metal Powders on Carbon Fibre Reinforced Polymers, Surf. Coat. Technol., 2017, 329, p 232-243

11. H. Che, M. Gagné, P.S.M. Rajesh, J.E. Sapieha, F. Sirois, D. Therriault, and S. Yue, Metallization of Carbon Fibre Reinforced Polymer for Lightning Strike Protection, J. Mater. Eng. Perform., 2018, 27(10), p 5205-5211

12. F. Robitaille, M. Yandouzi, S. Hind, and B. Jodoin, Metallic Coating of Aerospace Carbon/Epoxy Composites by the Pulsed Gas Dynamic Spraying Process, Surf. Coat. Technol., 2009, 203(19), p 2954-2960

13. P.S.M. Rajesh, F. Sirois, and D. Therriault, Damage Response of Composites Coated with Conducting Materials Subjected to Emulated Lightning Strikes, Mater. Des., 2018, 139, p 45-55

14. H. Assadi, F. Gärtner, T. Stoltenhoff, and H. Kreye, Bonding Mechanism in Cold Gas Spraying, Acta Mater., 2003, 51(15), p 4379-4394
15. M. Grujicic, J.R. Saylor, D.E. Beasley, W.S. DeRosset, and D. Helfritch, Computational Analysis of the Interfacial Bonding Between Feed-Powder Particles and the Substrate in the ColdGas Dynamic-Spray Process, Appl. Surf. Sci., 2003, 219(3-4), p 211-227

16. M. Grujicic, C.L. Zhao, W.S. DeRosset, and D. Helfritch, Adiabatic Shear Instability Based Mechanism for Particles/Substrate Bonding in the Cold-Gas Dynamic-Spray Process, Mater. Design, 2004, 25(8), p 681-688

17. S. Kumar, G. Bae, and C. Lee, Deposition Characteristics of Copper Particles on Roughened Substrates Through Kinetic Spraying, Appl. Surf. Sci., 2009, 255(6), p 3472-3479

18. T. Schmidt, H. Assadi, F. Gärtner, H. Richter, T. Stoltenhoff, H. Kreye, and T. Klassen, From Particle Acceleration to Impact and Bonding in Cold Spraying, J. Therm. Spray Tech., 2009, 18(5-6), p 794-808

19. T. Hussain, D.G. McCartney, P.H. Shipway, and D. Zhang, Bonding Mechanisms in Cold Spraying: The Contributions of Metallurgical and Mechanical Components, J. Therm. Spray Tech., 2009, 18(3), p 364-379

20. H. Che, X. Chu, P. Vo, and S. Yue, Metallization of Various Polymers by Cold Spray, J. Therm. Spray Technol., 2018, 27(12), p 169-178

21. A. Ganesan, M. Yamada, and M. Fukumoto, Cold Spray Coating Deposition Mechanism on the Thermoplastic and Thermosetting Polymer Substrates, J. Therm. Spray Tech., 2013, 22(8), p 12751282

22. M. Fukumoto, M. Mashiko, M. Yamada, and E. Yamaguchi, Deposition Behavior of Copper Fine Particles onto Flat Substrate Surface in Cold Spraying, J. Therm. Spray Tech., 2010, 19(1), p 89-94

23. X. Chu, H. Che, P. Vo, R. Chakrabarty, B. Sun, J. Song, and S. Yue, Understanding the Cold Spray Deposition Efficiencies of 316L/Fe Mixed Powders by Performing Splat Tests onto AsPolished Coatings, Surf. Coat. Technol., 2017, 324, p 353-360

24. M. Gardon, A. Latorre, M. Torrell, S. Dosta, J. Fernández, and J.M. Guilemany, Cold Gas Spray Titanium Coatings onto a Biocompatible Polymer, Mater. Lett., 2013, 106(3), p 97-99

25. C. Chen, X. Xie, Y. Xie, X. Yan, C. Huang, S. Deng, Z. Ren, and H. Liao, Metallization of Polyether Ether Ketone (PEEK) by Copper Coating via Cold Spray, Surf. Coat. Technol., 2018, 342, p 209-219

26. H. Ye and J. Wang, Preparation of Aluminum Coating on Lexan by Cold Spray, Mater. Lett., 2014, 137, p 21-24

27. X.L. Zhou, A.F. Chen, J.C. Liu, X.K. Wu, and J.S. Zhang, Preparation of Metallic Coatings on Polymer Matrix Composites by Cold Spray, Surf. Coat. Technol., 2011, 206(1), p 132-136

28. R. Lupoi and W. O'Neill, Deposition of Metallic Coatings on Polymer Surfaces Using Cold Spray, Surf. Coat. Technol., 2010, 205(7), p 2167-2173

29. T. Stoltenhoff, H. Kreye, and H.J. Richter, An analysis of the Cold Spray Process and its Coatings, J. Therm. Spray Tech., 2002, 11(4), p 542-550

30. T. Schmidt, F. Gärtner, H. Assadi, and H. Kreye, Development of a Generalized Parameter Window for Cold Spray Deposition, Acta Mater., 2006, 54(3), p 729-742

31. B.A. Doeser, S.W. Thomas, and J.R. Moon, Thermal Etching of Copper, Acta Metall., 1976, 24(8), p 773-778

32. E. Seedhouse, Martian Outpost: The Challenges of Establishing a Human Settlement on Mars, Praxis, 2009, p 261-275

33. M. Biron, Chap. 4-Detailed Accounts of Thermoplastic Resins, Thermoplastics and Thermoplastic Composites, 2nd ed., William Andrew Publishing, 2013, p 189-714 